\title{
Systemic p53 Gene Therapy of Cancer with Immunolipoplexes Targeted by Anti-Transferrin Receptor ScFv
}

\author{
Liang Xu, Wen-Hua Tang,* Cheng-Cheng Huang, * William Alexander, Lai-Man Xiang, Kathleen F. \\ Pirollo, Antonina Rait and Esther H. Chang
}

Department of Oncology, Lombardi Cancer Center, Georgetown University Medical Center, Washington D.C. Accepted September 5, 2001

\begin{abstract}
Background: A long-standing goal in genetic therapy for cancer is a systemic gene delivery system that selectively targets tumor cells, including metastases. Here we describe a novel cationic immunolipoplex system that shows high in vivo gene transfer efficiency and antitumor efficacy when used for systemic p53 gene therapy of cancer.

Materials and Methods: A cationic immunolipoplex incorporating a biosynthetically lipid-tagged, anti-transferrin receptor single-chain antibody (TfRscFv), was designed to target tumor cells both in vitro and in vivo. A human breast cancer metastasis model was employed to evaluate the in vivo efficacy of systemically administered, TfRscFv-immunolipoplex-mediated, p53 gene therapy in combination with docetaxel.

Results: The TfRscFv-targeting cationic immunolipoplex had a size of $60-100 \mathrm{~nm}$, showed enhanced tumor cell binding, and improved targeted gene delivery and transfection efficiencies, both in vitro and in vivo. The p53 tumor suppressor gene was not only systemically delivered by the immunolipoplex to human tumor xenografts in nude mice but also functionally expressed. In the nude mouse breast cancer metastasis model, the combination of the
\end{abstract}

p53 gene delivered by the systemic administration of the TfRscFv-immunolipoplex and docetaxel resulted in significantly improved efficacy with prolonged survival.

Conclusions: This is the first report using scFv-targeting immunolipoplexes for systemic gene therapy. The TfRscFv has a number of advantages over the transferrin (Tf) molecule itself: (1) ScFv has a much smaller size than Tf producing a smaller immunolipoplex giving better penetration into solid tumors; (2) unlike Tf, the ScFv is a recombinant protein, not a blood product; (3) large scale production and strict quality control of the recombinant scFv, as well as scFv-immunolipoplex, are feasible. The sensitization of tumors to chemotherapy by this tumor-targeted and efficient p53 gene delivery method could lower the effective dose of the drug, correspondingly lessening the severe side effects, while decreasing the possibility of recurrence. Moreover, this approach is applicable to both primary and recurrent tumors, and more significantly, metastatic disease. The TfRscFv-targeting of cationic immunolipoplexes is a promising method of tumor targeted gene delivery that can be used for systemic gene therapy of cancer with the potential to critically impact the clinical management of cancer.

\section{Introduction}

As we enter the new millennium, effective treatment of human cancers remains a challenge. With the recent advancements in human genomics and cancer genetics, molecular therapy, especially gene therapy, is becoming a promising strategy for the treatment of cancer (1-3). A long-standing goal in gene therapy for cancer is a stable, low toxic, systemic gene delivery system that selectively targets tumor cells, including metastases (4). Current gene therapy approaches employ either viral or non-viral vector systems (5). Progress has been made toward developing non-viral, pharmaceutical formulations of genes for in vivo human therapy, particularly cationic liposome-mediated gene transfer systems (6-8). One

Address correspondence and reprint requests to: Esther H. Chang, Lombardi Cancer Center, The Research Building/E420, Georgetown University Medical Center, 3970 Reservoir Road NW, Washington D.C. 20007. Phone: 202-687-8418; fax: 202-687-8434; e-mail: change@gunet.georgetown.edu. *These authors contributed equally to the study. disadvantage of cationic liposomes is that they lack tumor specificity and have relatively low transfection efficiencies as compared to viral vectors. However, this can be dramatically improved when the liposomes bear a ligand recognizing a cell surface receptor (9). Transferrin receptors (TfR) levels are elevated in various types of cancer cells $(10,11)$ and correlate with the aggressive or proliferative ability of tumor cells (12). Therefore, TfR levels are considered useful as a prognostic tumor marker, and TfR is a potential target for drug delivery in the therapy of malignant cells $(13,14)$. In our laboratory, we have developed transferrin-targeting cationic liposomes with tumor cell transfection efficiencies of $60 \%-70 \%$ in squamous cell carcinoma of head and neck, as compared to only $5-20 \%$ by cationic liposomes without the targeting ligand (15). This system was shown to have the capability of systematically delivering the p53 tumor suppressor gene to pre-established xenograft tumors and sensitizing them to radiotherapy, resulting in long term tumor regression in animals receiving the combination radiotherapy (16). 
In further developing a targeted gene delivery system aimed at the TfR, we have established a cationic immunolipoplex system directed by a single-chain antibody $\mathrm{Fv}$ fragment against the human transferrin receptor (TfRscFv). The TfRscFv targets the cationic liposome-DNA complex (lipoplex) to tumor cells and enhances the transfection efficiencies both in vitro and in vivo. In a nude mouse breast cancer metastasis model systemic p53 tumor suppressor gene therapy mediated by the TfRscFvtargeting immunolipoplexes, in combination with conventional chemotherapy, significantly prolonged the life-span and resulted in long term survival of the animals.

\section{Materials and Methods}

The $\mathrm{p} 53$ expression plasmid, pCMVp53, contains the human wild-type (wt) p53 gene under the control of the cytomegalovirus (CMV) promoter (16). The control plasmid, pVec, is the empty vector without the p53 insert. The plasmid pBP100 used to detect the functional expression of wtp53 was kindly provided by Dr. Arnold Levine, Rockefeller University, NY. The cationic lipids, dioleoyltrimethylammonium propane (DOTAP), dimethyldioctadecylammonium bromide (DDAB) and the fusogenic neutral lipid dioleolyphosphatidylethanolamine (DOPE), or cholesterol (Chol), were purchased from Avanti Polar Lipids, Inc. (Alabaster, AL).

Human head and neck cancer cell line JSQ-3, derived from a tumor of the nasal vestibule that failed radiotherapy, was maintained in Minimum Essential Medium with Earle's salts (EMEM), supplemented as previously described (15). This cell line, a kind gift from Dr. Raplph Weichselbaum, University of Chicago, was maintained in Improved Minimum Essential Medium (IMEM) with 10\% FBS plus $50 \mu \mathrm{g} /$ $\mathrm{ml}$ each of penicillin, streptomycin and neomycin and $2 \mathrm{mM}$ L-glutamine. Human prostate cancer cell line DU145 was maintained in EMEM with $10 \%$ FBS plus $50 \mu \mathrm{g} / \mathrm{ml}$ each of penicillin, streptomycin and neomycin and $2 \mathrm{mM}$ L-glutamine. Both cell lines were purchased from ATCC. All three cell lines have mutant $\mathrm{p} 53$.

\section{Construction of the Expression Vector for Anti-TfR scFv}

To construct the expression vector we used the vector pLP1 kindly provided by Dr. John de Kruif (Utrecht University, The Netherlands). This vector contains an amino acid linker sequence between the E. coli lipoprotein signal peptide (LPP) and the scFv cloning site $(17,18)$, and also contains both c-myc and $\mathrm{His}_{6}$ tag sequences that can be used for purification and detection of the expressed scFv (Fig. 1). The plasmid pDFH2TvecOK containing the anti-TfR SCFv from the 5E9 antibody, which recognizes the human transferrin receptor (CD71)(19), was obtained from Dr. David Fitzgerald, NCI, NIH, Bethesda, MD. Since there are no convenient restriction enzyme sites for cloning of the

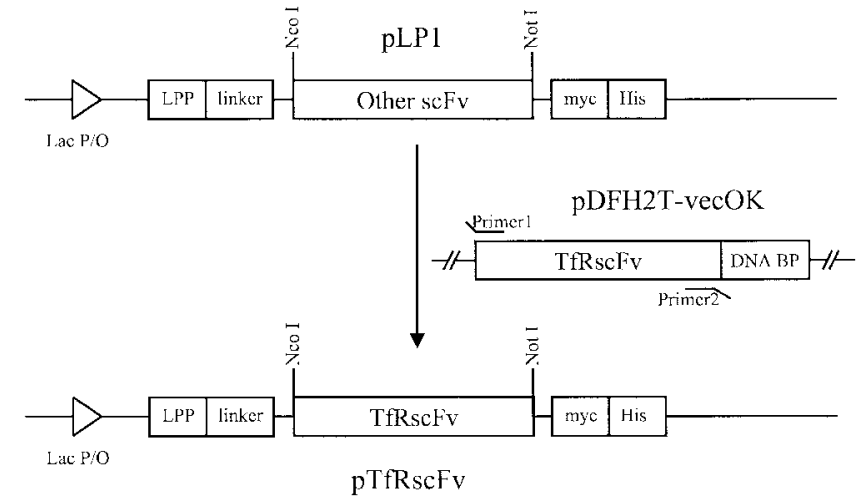

Fig. 1. Construction of pTfRscFv, the expression vector for the lipid-tagged anti-human transferrin receptor $\mathrm{ScFv}$ (TfRscFv). The vector pLPI contains an amino acid linker sequence between the E. coli lipoprotein signal peptide and the scFv cloning site (LPP and linker), and also contains both c-Myc and $\mathrm{His}_{6}$ tag sequences (myc and His). The PCRamplified TfRscFv cDNA from the vector pDFH2T-vecOK was cloned into pLPl using NcoI and NotI sites to obtain the expression vector, pTfRscFv.

TfRscFv sequence, PCR was carried out to amplify the ScFv cDNA from pDFH2T-vecOK. This PCR used a 5' primer (Primerl， 5'GGCCCATGGAGGTGCAGCTGGTGG $3^{\prime}$ ) containing a $N c o$ I site and a $3^{\prime}$ primer (Primer 2, 5' CCGGAATTCGCGGCCGCTTTTATCTCCAGCTTGGTC $3^{\prime}$ ) containing a NotI site, as shown in Fig. 1. The TfRscFv cDNA was then cloned into pLPl using NcoI and NotI sites to obtain the expression vector for the lipid-tagged TfRscFv, pTfRscFv (Fig. 1).

\section{Expression and Purification of TfRscFv}

The TfRscFv was expressed in the pTfRscFvtransformed expression host SF1 10F' after overnight induction with ImM IPTG. The TfRscFv protein was isolated from the bacterial membrane using Triton $\mathrm{X}-100$ as described by de Kruif et al (18). The TfRscFv was purified from the detergent-solubilized membranes by metal-chelating chromatography with a HiTrap column (Pharmacia), which binds the His6 tag on the expressed TfRscFv. The TfRscFv was stored in $20 \mathrm{mM}$ HEPES, $150 \mathrm{mM} \mathrm{NaCl}, \mathrm{pH} 7.4$, containing $1 \%$ n-octyl $\beta$-D-glucoside (OG) (Sigma), at a concentration of $1 \mathrm{mg} / \mathrm{ml}$.

Preparation of the TfRscFv-immunolipoplexes by Lipid-film Solubilization Method

$5 \mu$ mol lipids (DOTAP/DOPE, 1:1 molar ratio, for LipA) in chloroform were evaporated under reduced pressure to obtain a dry lipid film in a glass roundbottom flask. To the lipid film was added $500 \mu \mathrm{g}$ TfRscFv in $0.5 \mathrm{ml} 20 \mathrm{mM}$ HEPES, $150 \mathrm{mM} \mathrm{NaCl}, \mathrm{pH}$ 7.4, containing $1 \%$ OG, incubated 10-20 minutes at room temperature and then vortexed to solubilize the lipid membrane. $2 \mathrm{ml}$ sterile water was added to dilute the TfRscFv-lipid mixture. The solution was briefly sonicated to clarity in a bath-type sonicator at 
$20^{\circ} \mathrm{C}$. The resultant TfRscFv-liposome is an almost clear solution with a limited amount of residual OG detergent. The immunoliposomes made by this method are designated TfRscFv-LipAl.

\section{Preparation of TfRscFv-immunolipoplexes by the Direct Anchoring Method}

The preformed cationic liposomes were prepared basically as previously described $(15,16)$. Briefly, $10 \mathrm{ml}$ pure water was added to $20 \mu \mathrm{mol}$ lipids prepared as dry lipid film in a glass round-bottom flask and sonicated in a bath-type sonicator for 10-30 min at room temperature (for liposomes containing DOPE) or at $65^{\circ} \mathrm{C}$ (for liposomes containing cholesterol (Chol)). The cationic liposomes prepared were almost clear solutions. Their lipid compositions and molar ratios were as follows: (1) LipA: DOTAP:DOPE, 1:1; (2) LipB: DDAB:DOPE, 1:1; (3) LipC: DOTAP:Chol, 1:1. For attaching TfRscFv to the preformed liposomes, various amount of TfRscFv in $20 \mathrm{mM}$ HEPES, 150 $\mathrm{mM} \mathrm{NaCl}, \mathrm{pH} 7.4$, containing $1 \%$ OG, was added to the liposomes while vortexing, at volume ratios from $1: 3$ to $1: 10$. The mixture was vortexed for approximately 5-10 minutes more to obtain a clear TfRscFv-immunoliposome solution, designated TfRscFv-LipA2.

\section{Immunoreactivity of TfRscFv-immunoliposomes Determined} by ELISA and Immunofluorescence

Indirect cellular enzyme-linked immunosorbent assay (ELISA) was employed to determine the immunoreactivity of the TfRscFv before and after attachment to liposomes. Confluent JSQ-3 cells in 96-well plates were fixed with $0.5 \%$ Glutaraldehyde in PBS for $10 \mathrm{~min}$ at room temperature. The plate was blocked with $5 \%$ fetal bovine serum (FBS) in PBS at $37^{\circ} \mathrm{C}$ for $30 \mathrm{~min}$. The TfRscFv, TfRscFvimmunoliposomes or unliganded liposomes were added to each well in duplicate and incubated at $4^{\circ} \mathrm{C}$ overnight. After three PBS-washes, the anti-c-myc monoclonal antibody, 9E10 $(10-30 \mu \mathrm{g} / \mathrm{ml}$ in PBS with $3 \%$ FBS) was added to each well and incubated at $37^{\circ} \mathrm{C}$ for $60 \mathrm{~min}$. After three PBS-washes, HRP-labeled goat-anti-mouse IgG (Sigma) diluted 1:1000 in PBS with 3\% FBS, was added to each well and incubated for $30 \mathrm{~min}$ at $37^{\circ} \mathrm{C}$. The plate was washed three times with PBS and $100 \mu \mathrm{l}$ of the substrate, $0.4 \mathrm{mg} / \mathrm{ml}$ OPD in citrate phosphate buffer (Sigma), was added to each well. The colordevelopment was stopped by adding $100 \mu \mathrm{l} 2 \mathrm{M}$ sulfuric acid to each well. The plate was read by an ELISA plate reader (Molecular Devices Corp.) at $490 \mathrm{~nm}$.

For immunofluorescent staining studies, TfRscFvLipAl or TfRscFv-LipA2, free TfRscFv, non-targeted LipA, or FITC-labled human transferrin (Tf-FITC) were incubated with the tumor cells (JSQ-3 or DU 145) for 60 min on ice. After three washes with icecold PBS/3\% FBS, the second antibody, anti-c-Myc monoclonal antibody 9E10 (Pharmacia) which binds the c-Myc sequence in the c-terminus of TfRscFv, was added at $30 \mu \mathrm{g} / \mathrm{ml}$ and incubated on ice for 45-60 min. After three washes with ice-cold PBS/3\% FBS, the cells were stained with FITC-labeled sheepanti-mouse IgG (Sigma), 1:60 dilution in PBS/5\% FBS, for $30 \mathrm{~min}$ on ice. The cells were then washed and fixed with $0.4 \%$ paraformaldehyde at $4^{\circ} \mathrm{C}$ overnight. The stained cells were analyzed on a FACStar flow cytometer (Becton \& Dickinson, Franklin Lakes, NJ).

\section{In Vitro Gene Transfection}

Liposome-mediated gene transfection of tumor cells was performed as described previously $(15,16,20)$. In these studies the reporter construct used contained the E. coli. Lac $\mathrm{Z}$ gene under the control of the CMV promoter (pCMVb), the same promoter used in pCMVp53 (16). TfRscFv-liposomes made at a concentration of $1.8 \mathrm{mM}$ lipids and varying amounts of protein (16 to $22 \mu \mathrm{g} / \mu \mathrm{mol}$ lipids) were mixed with plasmid DNA at a ratio of $1 \mu \mathrm{g}$ DNA/8$14 \mathrm{nmol}$ lipids, in a manner similar to our other ligand-liposomes (20). Co-transfection of pCMVp53 with an expression plasmid (pBP100) which contains the luciferase reporter gene under the control of a p53 responsive promoter, was performed essentially as previously reported with some modifications (21). Briefly, Tf-LipA complexed to $0.3 \mu \mathrm{g} /$ well of pBP100 (Tf-LipA-BP100) was added to JSQ-3 cells seeded in a 24 well plate as previously described (15). Subsequently, $0.3 \mu \mathrm{g}$ DNA/ well of TfRscFv-LipA2-p53, TfRscFv-LipA2-pVec or TfRscFv-LipA2 minus DNA (equivalent lipids) were added in triplicate. The co-transfection was performed identically to that for other reporter genes and the luciferase activity was assayed 48 hours later $(15,16,20)$.

\section{In Vivo Studies}

For in vivo p53 gene delivery studies, nude mouse xenografts were induced by the subcutaneous injection of $2.5 \times 10^{6} \mathrm{JSQ}-3$ cells on the lower back above the tail of 4-6 week old female athymic nude ( $\mathrm{NCr}$ $\mathrm{nu} / \mathrm{nu}$ ) mice. The TfRscFv-LipA2 was prepared by the direct anchoring method at a final concentration of $1.8 \mathrm{mM}$ lipids and $20 \mu \mathrm{g} / \mathrm{ml}$ protein. The TfRscFvLipA2-pCMVp53 immunolipoplex was prepared by adding pCMVp53 DNA to TfRscFv-LipA2 at a ratio of $1 \mu \mathrm{g}$ DNA/14nmol lipids. $25 \mu \mathrm{g}$ pCMVp53 complexed with either TfRscFv-LipA2 or non-targeted liposomes (total volume $0.3 \mathrm{ml}$ ) were intravenously injected into tumor-bearing nude mice via tail vein. Two days after injection, the tumors as well as major organs, were excised and the $\mathrm{p} 53$ protein expression was assessed by Western analysis as previously described (16).

For in vivo efficacy studies, a nude mouse tumor metastasis model was employed (22). 435/LCC6 cells $\left(8 \times 10^{6}\right)$ were intravenously injected into 4-6 wk old female athymic nude mice. Ten days later, the 
mice were randomly divided into 5 mice/group and systemic treatment with TfRscFv-LipA2-pCMVp53, with or without docetaxel (Taxotere $^{\mathrm{TM}}$, RhonePoulenc Roprer Pharmaceuticals, Inc., Collegeville, PA), was begun. Intravenous injections of the complex, at a DNA dose of $20 \mu \mathrm{g} / 0.3 \mathrm{ml}$ per i.v., were administered twice a week, for a total of 10 injections. The immunolipoplexes were freshly prepared before each injection by mixing pCMVp53 DNA with TfRscFv-LipA2 at a ratio of $1 \mu \mathrm{g}$ DNA/14nmol lipids. As controls, groups of mice were also treated with docetaxel alone, with the untargeted LipA-pCMVp53 plus drug, or with the human transferrin-targeting lipoplex Tf-LipA-pCMVp53, with or without drug. The Tf-LipA-pCMVp53 was prepared as previously described (16). For combination treatment groups, docetaxel stock of $10 \mathrm{mg} / \mathrm{ml}$ was added directly to the liposome-DNA solutions before injection to reach a dose of $7.5 \mathrm{mg} / \mathrm{kg}$ body weight. A separate study indicated that adding stock docetaxel directly to immunolipoplex solution did not change the integrity and size of the complex (data not shown). All solutions for i.v. injection were labeled with Solution Numbers and administered by the technicians from the Georgetown University Animal Facility without knowledge of their individual contents. The animal deaths were recorded daily. All animal experiments were performed in accordance with Georgetown University institutional guidelines for the care and use of animals.

\section{Characterization of TfRscFv-immunoliposomes and Immunolipoplexes}

The sizes and zeta potentials of the TfRscFv-Lip and TfRscFv-LipA-pCMVp53 were analyzed by photon correlation spectroscopy (PCS) using the Malvern Zetasizer $3000 \mathrm{HS}$ (Malvern Instruments, Inc., UK). The measurement was performed according to the manufacturer's instruction with the following settings: temperature $25^{\circ} \mathrm{C}$; scattering angle 90; analysis mode CONTIN. Each measurement was repeated 2-3 times for size and 5-8 times for zeta potential. The results are presented as the mean \pm SE of at least three preparations.

\section{Statistical Analysis}

The student's $t$-test was used for comparison of in vitro data. For in vivo nude mice efficacy studies, the Kaplan-Meier Survival Analysis was performed using GraphPad Prism 3.02, GraphPad Software, San Diego, CA. The Mantel-Haenszel Logrank Test from the same software package was employed for comparison of individual survival curves.

\section{Results}

Expression of Anti-TfR scFv

To facilitate subsequent preparation of immunoliposomes, the biosynthetically lipid-tagged scFv system described by Laukkanen et al. (17) and de
Kruif et al. (18) was employed. Fig. 1. shows the construction of the expression vector for the lipidtagged $\mathrm{scFv}$, designated TfRscFv. In this expression vector construct, a sequence for the E. coli lipoprotein signal peptide and the E. coli lipoprotein $\mathrm{N}$-terminal 9 amino acids (LPP) were inserted as described by Laukkanen et al. $(23,24)$. The insertion of these sequences will lead to fatty acid acylation of the expressed signal peptide on the ScFv in the E. coli host and its insertion into the bacterial membrane (17). Purification of the lipid modified ScFv from the bacterial membrane results in an active molecule that can attach to liposomes via its lipid tag $(18,23,24)$. The purified TfRscFv was analyzed by SDS-PAGE and Western Blot using anti-c-Myc antibody 9E10, with the TfRscFv showing a band of the size of about $30 \mathrm{kDa}$ (data not shown).

\section{Preparation of TfRscFv-targeted Cationic Immunoliposomes} and Immunolipoplexes

The lipid-tagged TfRscFv-immunoliposomes are prepared basically by two methods: a lipid-film solubilization method and a direct anchoring method. The lipid-film solubilization method is modified from the detergent dialysis method, which was originally described by Laukkanen et al. (24) and de Kruif et al. (18) for neutral or anionic liposomes. This method has been found to be suitable for attaching lipid-tagged TfRscFv to cationic liposomes as well. The second method for attaching lipid-tagged antibody fragments is the direct anchoring method that is particularly useful for attaching the TfRscFv to only the outer surface of preformed liposomes. The remaining OG and the unincorporated TfRscFv can be removed by column chromatography with Sepharose CL-4B or Sephacryl S-500. However, separation experiments, i.e., ultrafiltration with Centricon-100 (Amicon), or Sepharose CL-4B (Pharmacia) chromatography, demonstrated that virtually all of the lipid-tagged TfRscFv molecules added have been attached or anchored to the cationic liposomes (data not shown). Therefore, it is unnecessary to have a further purification step to remove the unattached TfRscFv.

The TfRscFv-immunolipoplexes were prepared by mixing equal volumes of TfRscFv-immunoliposomes with plasmid DNA at various DNA/lipid ratios, either in serum-free medium for in vitro studies, or in water for in vivo experiments, as described in detail in Methods.

\section{Immunoreactivity of TfRscFv-immunoliposomes}

To analyze the immunoreactivity of TfRscFv before and after incorporation into cationic liposomes, indirect cellular ELISA was employed using human TfRpositive head and neck cell line JSQ-3 as the target cells. ELISA results are expressed as optical density at $490 \mathrm{~nm}$ (OD490), mean $\pm \mathrm{SD}, \mathrm{n}=2$. The immunoliposomes TfRscFv-LipAl and TfRscFv-LipA2 

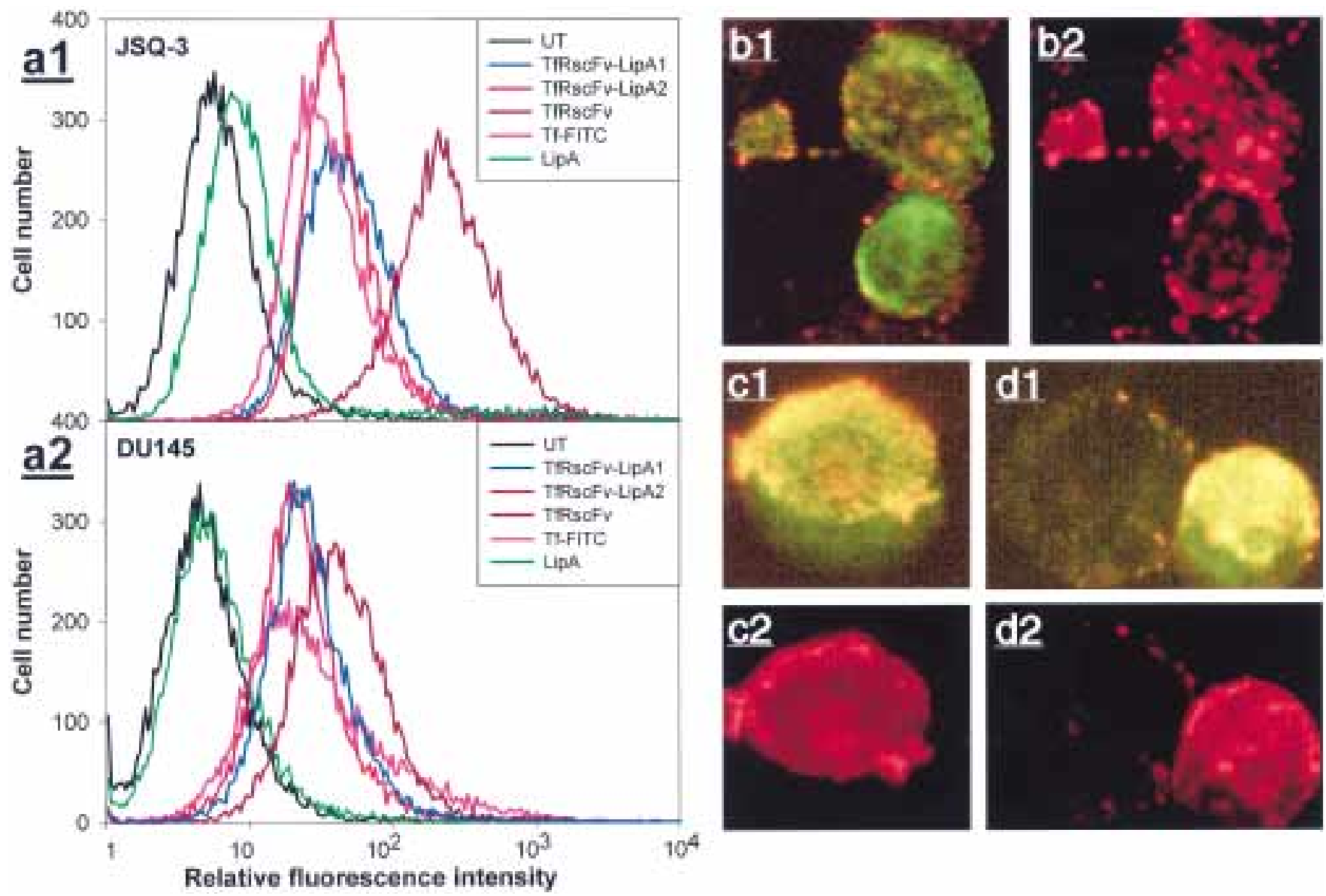

Fig. 2. Binding of TfRscFv-liposomes to tumor cells. The human head and neck cancer JSQ-3 cells (al) and prostate cancer DU145 cells (a2) were incubated with TfRscFv-LipA1, TfRscFv-LipA2, free TfRscFv, non-targeted liposomes (LipA) or FITC-labled human transferrin (Tf-FITC). After immunofluorescent staining with anti-c-Myc antibody followed with FITC-labeled sheep-anti-mouse IgG antibody, the cells were analyzed by flow cytometery. UT: untreated control cells. TfRscFv-LipAl and TfRscFv-LipA2 binds to tumor cells comparable to that observed with human transferrin. The stained cells were also observed under a fluorescence microscope. (b1), (cl) and (d1) are TfRscFv-LipA2-treated JSQ-3 cells observed with FITC filter, the green fluorescence indicates the presence of TfRscFv. (b2), (c2) and (d2) are the corresponding fields observed with rhodamine filter, the red fluorescence indicates the presence of liposomes.

yielded OD490 values of $1.134 \pm 0.038$ and $1.386 \pm$ 0.004 , respectively, similar to that of the free TfRscFv (1.024 \pm 0.037$)$. Unliganded liposome LipA had an OD490 value of only $0.142 \pm 0.036$. These results demonstrate that the TfRscFv retained its immunoreactivity after incorporation into liposomes. Pre-incubation with free cationic liposomes did not significantly reduce the binding of the immunoliposomes to the tumor cells, demonstrating that the binding is through the targeting ligand TfRscFv. The slightly higher binding activity of TfRscFv-LipA2 than TfRscFv-LipAl ( $p=0.0113)$ may be due to the fact that the direct anchoring method ensures virtually all TfRscFv added is incorporated into the outer surface of the liposomes, whereas the TfRscFv-LipAl made by the lipid-film solubilization method may have at best about $50 \%$ of TfRscFv on the surface.

Immunofluorescent staining followed by FACS analysis and fluorescent microscopy was also employed to assess the specific binding of TfRscFv- liposomes to the target cells. As shown in Fig. 2 (al), incubation of JSQ-3 cells with TfRscFv-LipAl or TfRscFv-LipA2 resulted in a fluorescence shift identical to that observed with Tf-FITC, indicating the tumor cell binding of the immunoliposome. TfRscFv-LipAl showed the same binding activity to tumor cells as TfRscFv-LipA2. Similar results were also observed with prostate tumor cell line DU145 (Fig. 2 a2). Indirect immunofluorescent staining with TfRscFv-liposomes (where liposomes had been labeled with rhodamine-DOPE) confirmed the binding of TfRscFv-targeting liposomes to JSQ-3 cells (Fig. 2 b-d). The TfRscFv-LipA2-treated JSQ-3 cells showed the concurrence of the green fluorescence (indicating the presence of TfRscFv, Fig. $2 \mathrm{bl}, \mathrm{cl}$, d1) and red fluorescence (indicating the presence of liposomes, shown in Fig. 2 b2, c2, d2). The results demonstrate that TfRscFv does indeed direct the binding of liposomes to the tumor cells. In addition, TfRscFv-LipA2 showed substantial binding to 
tumor cells, demonstrating that incorporation into the liposome complex did not inactivate the immunological activity of TfRscFv, and that TfRscFv can direct liposomes to bind to target tumor cells.

\section{Optimization of Tfrscfv-Immunoliposome-Mediated Gene Transfection of Tumor Cells In Vitro}

To assess the transfection efficiency of TfRscFvliposomes, in vitro transfection experiments were performed with plasmid pCMVb that uses the E. coli LacZ gene as a reporter (20). The level of LacZ gene expression in transfected JSQ-3 cells (correlating with transfection efficiency) was assessed by $\beta$-galactosidase $(\beta$-Gal) enzymatic assay $(15,16)$. As shown in Fig. 3, the attachment of TfRscFv significantly increased the transfection efficiency of cationic liposomes 2- to 2.4-fold over that observed with the non-targeted liposomes (TfRscFv-LipAl vs. LipA, $\mathrm{p}=0.005 ;$ TfRscFv-LipA2 vs. LipA, $\mathrm{p}=0.0119 ;$ two-tailed $t$-test). This increase in gene transfection is comparable to that of human transferrin. Here too we observed higher efficiency with TfRscFvLipA2 than with TfRscFv-LipAl, correlating with their immunoreactivities in the ELISA results described above. The difference observed here might also be due to more TfRscFv being present on the surface of TfRscFv-LipA2 immunoliposomes. Thus, subsequent experiments focused on TfRscFv-LipA2 made by the direct anchoring method.

To examine the effects of DNA/lipid ratio and lipid composition on the transfection efficiencies of the immunolipoplexes, JSQ-3 cells were transfected with TfRscFv-targeting cationic lipoplexes

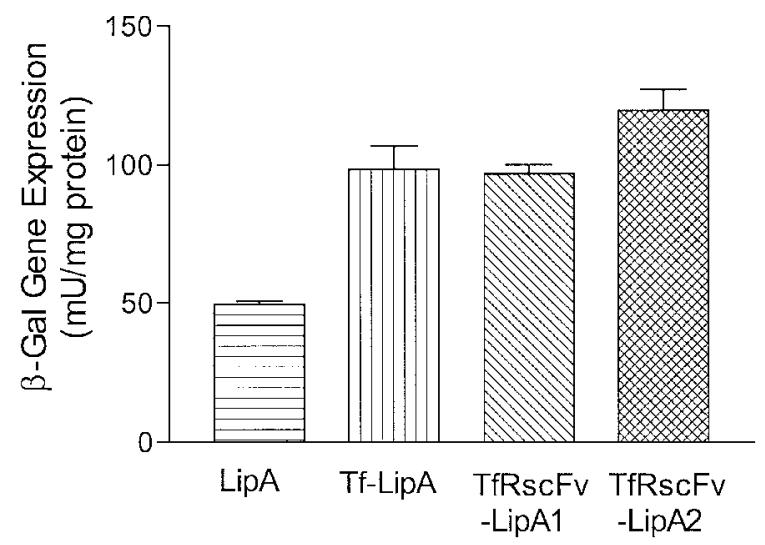

Fig. 3. TfRscFv facilitated liposome-mediated gene transfection of JSQ-3 tumor cells in vitro. Transfection efficiency was assessed by the $\beta$-galactosidase enzymatic assay and is given as $\mathrm{mU} \beta$-galactosidase/mg protein $(15,16)$. The attachment of TfRscFv significantly increased the transfection efficiency of cationic liposomes, (2- to 2.4-fold) as compared to non-targeted LipA. The gene transfection efficiency of TfRscFvLipAl (prepared by the lipid-film solubilization method) or TfRscFv-LipA2 (prepared by the direct anchoring method) is comparable to that of the human transferrin targeting lipoplex (Tf-LipA). TfRscFv-LipA2 showed slightly higher transfection efficiency than TfRscFv-LipAl, correlating with their immunoreactivities in the ELISA results in Fig. 2.

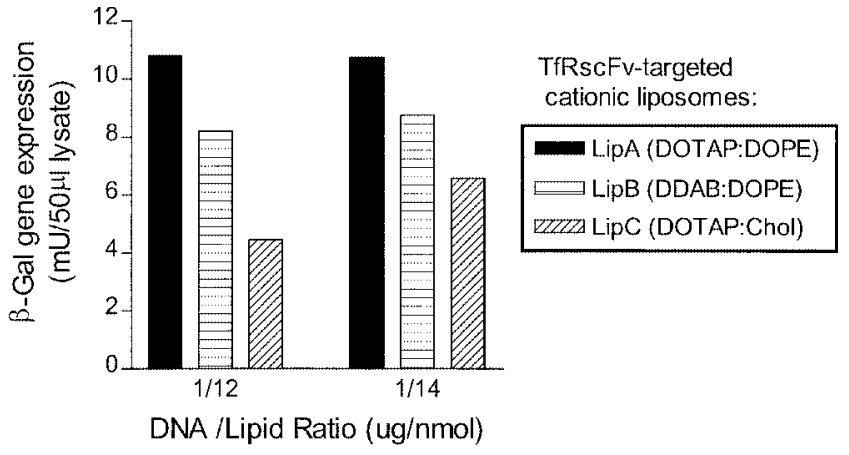

Fig. 4. Effects of DNA/lipid ratio and lipid composition on the transfection efficiencies of TfRscFv-

immunolipoplexes. JSQ-3 cells were transfected with TfRscFv-targeting cationic lipoplexes prepared with different lipid compositions and at various DNA/lipid ratios, using the LacZ gene as the reporter (16). TfRscFv-LipA showed superior transfection activity over TfRscFv-targeting LipB or LipC. DNA/lipid ratios at $1 / 12$ to $1 / 14 \mu \mathrm{g} / \mathrm{nmol}$ gave the best and similar efficiencies in vitro.

prepared with different lipid compositions and at various DNA/lipid ratios $(16,20)$. As shown in Fig. 4, TfRscFv-targeted LipA (DOTAP:DOPE, molar ratio $1: 1)$ showed superior transfection activity over other liposome compositions, i.e., LipB (DDAB:DOPE) or LipC (DOTAP:Chol) (molar ratio 1:1). The liposome composition LipA was therefore chosen for further optimization. With this composition, DNA/lipid ratios at $1 / 12$ to $1 / 14 \mu \mathrm{g} / \mathrm{nmol}$ gave the best result and had similar efficiencies in vitro (Fig. 4).

To optimize TfRscFv-LipA2 mediated gene transfection, different amounts of TfRscFv were also incorporated into cationic liposomes by the direct anchoring, with final protein/lipids ratios of 16-22 $\mu \mathrm{g} / \mu \mathrm{mol}$. Both human breast cancer cell line MDAMB-435 and head and neck cell line JSQ-3 were transfected with TfRscFv-LipA2-pCMVb. Fig. 5 shows that TfRscFv-targeting liposomes gave 2- to 4-fold higher reporter gene expression than the nontargeted liposomes in both cell lines. The immunoliposomes with $22 \mu \mathrm{g}$ protein $/ \mu \mathrm{mol}$ lipids showed higher transfection efficiency, but in later in vivo experiments, they tended to precipitate and were not stable when complexed with DNA. Therefore, the $18-20 \mu \mathrm{g} / \mu \mathrm{mol}$ of TfRscFv/lipids were chosen as optimal ratios for further study.

To further confirm this optimized formulation for TfRscFv-immunolipoplexes, we employed a second reporter gene, the firefly luciferase gene in the plasmid pLuc, in the in vitro transfection assay. The transfection assay was carried out as previously described (16). Both MDA-MB-435 and prostate cancer cell line DU145 were transfected with TfRscFv-LipA2-pLuc. As shown in Fig. 6, the presence of the TfRscFv significantly increased the transfection efficiency of the cationic liposomes. Based on the recombinant luciferase standard (Sigma), the 


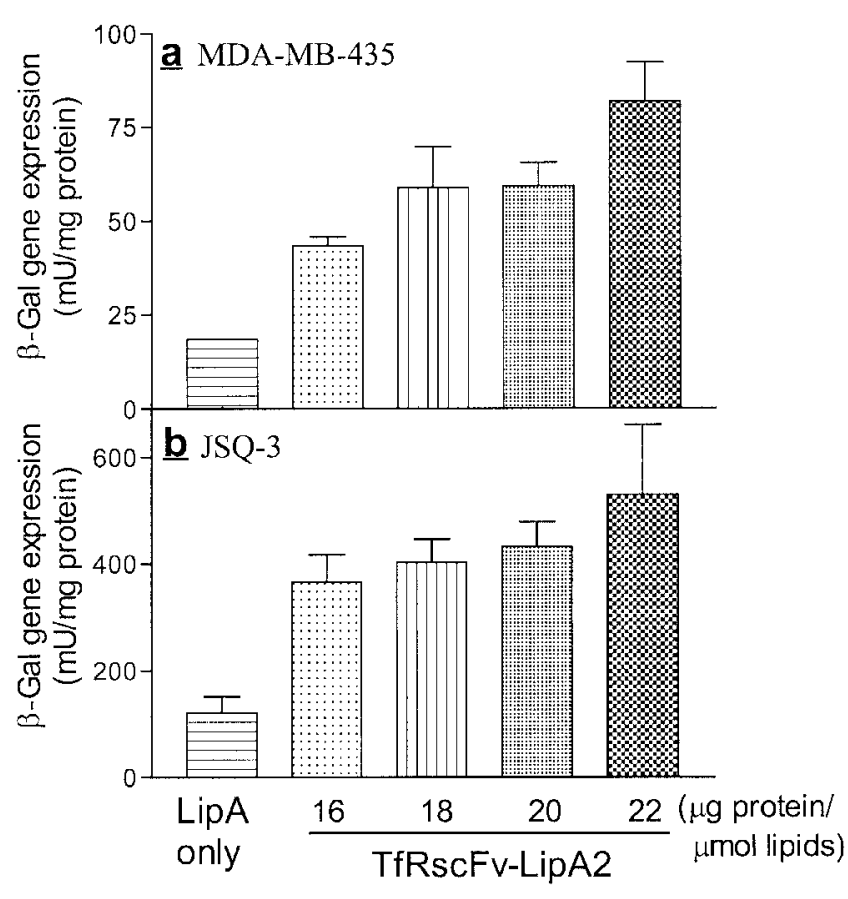

Fig. 5. Optimization of protein/lipid ratios for TfRscFvLipA2. Different amounts of TfRscFv were incorporated to cationic liposomes by the direct anchoring method, with final protein/lipids ratios of 16-22 $\mu \mathrm{g} / \mu \mathrm{mol}$. Human breast cancer cells MDA-MB-435 (a) and head and neck cancer cells JSQ-3 (b) were transfected as described in Methods.

resulting luciferase gene expression of 80,000 $\mathrm{RLU} / \mu \mathrm{g}$ protein in MDA-MB-435 cells and 40,000 $\mathrm{RLU} / \mu \mathrm{g}$ protein in DU145 cells, corresponded to $10 \%$ and $5 \%$ of total cellular protein, respectively. For both cell lines, the TfRscFv-immunolipoplexes were 10-fold more efficient than the unliganded LipA and 2- to 3-fold more efficient than Tf-targeting liposomes. Control SCFv (CTLSCFv)-LipA2 showed the same activity as LipA, demonstrating that this increased efficiency is via the specific targeting ligand, TfRscFv.

\section{Functional Exogenous P53 Expression In Tumor Cells Transfected By TfRscFv-LipA2-pCMVp53 Immunolipoplexes In Vitro}

The functional expression of exogenous wtp53 in JSQ-3 tumor cells transfected with the TfRscFvtargeting immunoliposomes was assessed by cotransfection of pCMVp53 with plasmid pBP100, which contains the luciferase reporter gene under the control of a p53 responsive promoter (21). Consequently, the higher the level of exogenous p53 expression, the higher the level of luciferase activity. Co-transfection experiments were performed by transfecting JSQ-3 cells with pBP100 complexed with Tf-LipA (Tf-LipA-pBP100) together with the same amount of pCMVp53 complexed with TfRscFvLipA2 (TfRscFv-LipA2-p53). To serve as controls, either TfRscFv-LipA2 without DNA (TfRscFv-LipA2

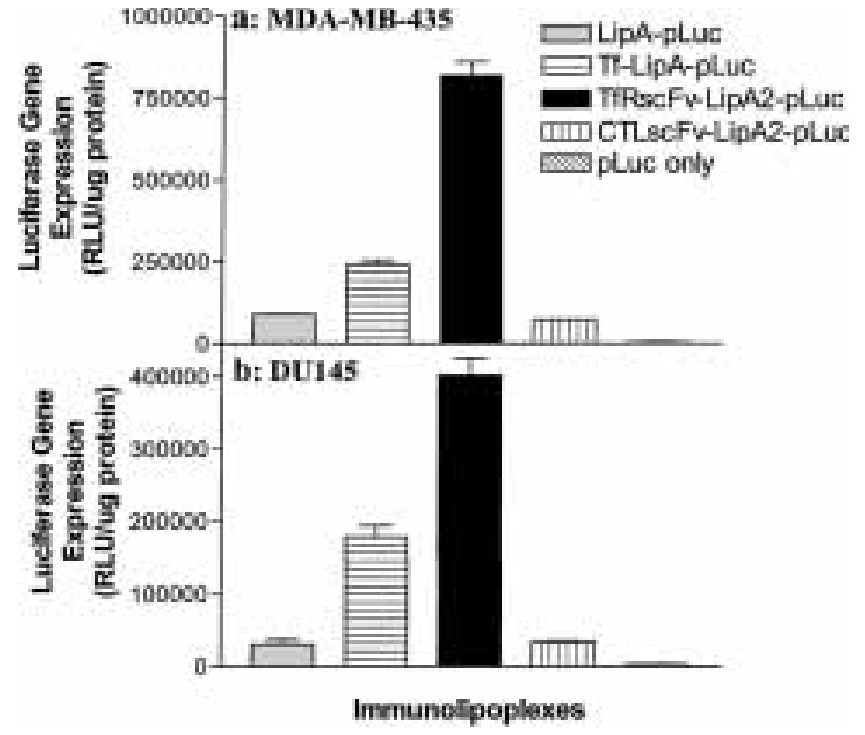

Fig. 6. TfRscFv-immunolipoplex-mediated gene transfection in vitro, using another reporter gene, the firefly luciferase gene. (a) Human breast cancer cell line, MDA-MB435. (b) Human prostate cancer cell line, DU 145. Transfection efficiency was assessed by the Luciferase assay and is given as relative light units(Rlu) $/ \mu \mathrm{g}$ protein, as previously described (16). The TfRscFv significantly increased the transfection efficiency of cationic liposomes. TfRscFv-LipA2-pLuc was 10-fold more efficient than non-targeted LipA-pLuc and 2- to 3-fold more efficient than Tf-LipA-pLuc. Control scFv (CTLscFv)LipA-pLuc showed the same activity as LipA-pLuc.

only) or complexed with the same amount of control plasmid pCMVpVec (TfRscFv-LipA2-pVec) were cotransfected with Tf-LipA-pBP100. Using TfRscFV as the targeting ligand for cationic liposomes increased the transfection efficiency and enhanced the expression of functional wtp 53 protein, indicated by the increased p53-responsive luciferase activity, as compared to non-targeting lipoplex LipA-p53 $(p=0.0263)$. As shown in Fig. 7, TfRscFv- LipA2-p53 co-transfection gave 54-fold more p53-responsive luciferase activity than TfRscFv-LipA2-pVec ( $p=$ 0.0001 ) and 11-fold more than TfRscFv-LipA2 only $(p=0.0002)$. Once again, the level of $p 53$ expression in the cells transfected with the TfRscFv-LipA2-p53 immunolipoplex was at least comparable to that with transferrin-targeting lipoplex $(p=0.0526)$ (Fig. 6). These results (Fig. 7) demonstrated that, via this targeted gene delivery system, exogenous wtp53 protein was expressed efficiently and functionally.

Characterization of the TfRscFv-targeting Immunolipoplexes

For characterization of the immunolipoplex, the sizes and zeta potential were measured by photon correlation spectroscopy (PCS), also known as dynamic laser light scattering (DLS). The immunolipoplex was prepared according to the optimized formulation for in vivo injection. The cationic liposome alone (LipA) had a size of $29.3 \pm 7.2 \mathrm{~nm}$ in 


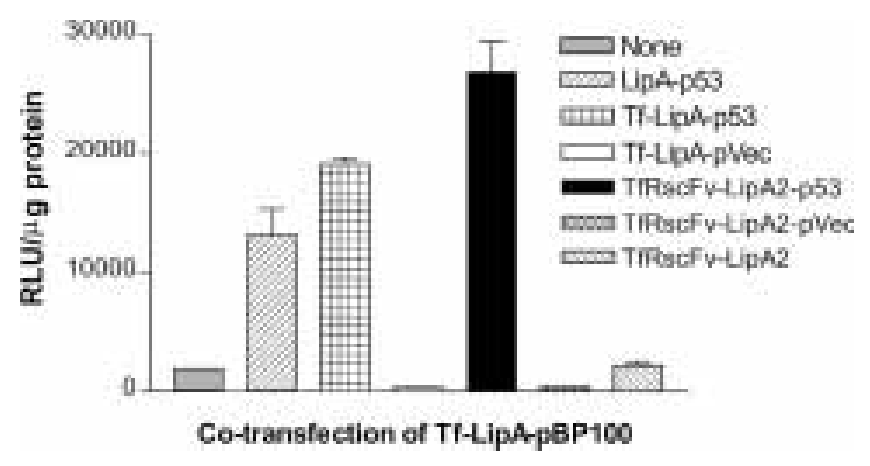

Fig. 7. Functional exogenous p53 expression in JSQ-3 cells transfected by TfRscFv-LipA2-p53 immunolipoplex in vitro. JSQ-3 cells were co-transfected in triplicate by Tf-LipAcomplexed plasmid pBP100, which contains the luciferase reporter gene under the control of a $\mathrm{p} 53$ responsive promoter (21), together with p53 plasmid complexed with TfRscFvLipA2. TfRscFv-LipA2-p53 co-transfection gave 54-fold more p53-responsive luciferase activity than TfrscFv-LipA2-pVec $(p=0.0001)$ and 11 -fold more than TfrscFv-LipA2 only $(p=0.0002)$, demonstrating that exogenous wtp53 protein was expressed functionally by this gene delivery system.

diameter (mean \pm S.D., $\mathrm{n}=3$ ). The incorporation of TfRscFv into the cationic liposome by the direct anchoring method, TfRscFv-LipA2, resulted in a size of $25.2 \pm 0.6 \mathrm{~nm}$ in diameter. Therefore, the incorporation of $\mathrm{TfRscFv}$ into the liposome did not cause significant change in liposomal size $(p>0.05)$. The size of the TfRscFv-LipA2 corresponds well to the $20-35 \mathrm{~nm}$ size of small unilamellar vesicles (SUV) (25). When complexed with plasmid DNA at an optimal DNA/lipid ratio of $1 \mu \mathrm{g} / 14 \mathrm{nmol}$, the immunolipoplex has a size of $92.9 \pm 8.9 \mathrm{~nm}$ in diameter and a net positive charge of $52.7 \pm 1.8 \mathrm{mV}(\mathrm{n}=3)$. More importantly, the immunolipoplex in 5\% dextrose is quite stable, with a size of $81.8 \pm 2.0 \mathrm{~nm} 24 \mathrm{hr}$ after preparation when stored at $4^{\circ} \mathrm{C}$. This difference in size is not significant when compared with the freshly prepared immunolipoplex $(\mathrm{p}>0.05)$.

\section{Systemic 53 Gene Delivery by TfRscFv-Immunolipoplex} in a Mouse Xenograft Tumor Model

To examine the ability of TfRscFv-targeting liposome to deliver the p53 gene systemically to tumor tissue in vivo, TfRscFv-LipA2-p53 or untargeted LipA-p53 was injected via tail vein into nude mice bearing JSQ-3 subcutaneous xenograft tumors. JSQ-3 is a squamous cell carcinoma of head and neck cell line with mutant p53 $(4,20)$. Two days after injection, as shown by Western analysis in Fig. 8, the tumor from the mouse injected with the TfRscFv-LipA2-p53 immunolipoplex displayed a very intense additional lower band. This is indicative of a high level expression of the exogenous wtp53 protein, represented by this slightly faster mobility p53 band. It should be noted that an intense endogenous p53 band was also observed. This
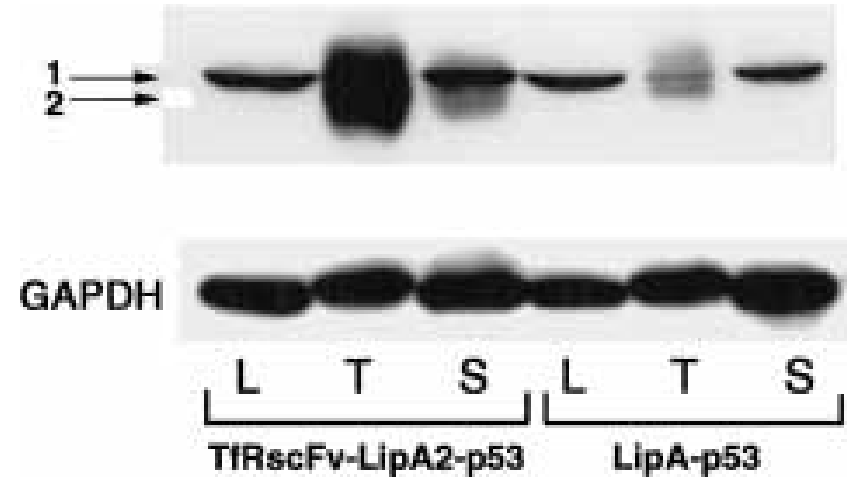

Fig. 8. Exogenous wtp53 expression in JSQ-3 xenograft tumors after i.v. injection of TfRscFv-LipA2-p53. Athymic nude mice carrying JSQ-3 xenograft tumors were i.v. injected with either TfRscFv-LipA2-p53 or the unliganded LipA-p53. 48 hrs later the animals were euthanized, the tumor, liver and skin excised, and protein isolated for Western analysis. $\mathrm{L}=$ liver; $\mathrm{T}=$ tumor; $\mathrm{S}=$ skin; Arrow $1=$ Endogenous p53; Arrow $2=$ Exogenous wtp53. This experiment was repeated three times with representative results shown here. A high level of expression of the exogenous wtp53 protein is evident in the tumor from the mouse injected with the TfRscFv-LipA2-p53 immunolipoplex, while only limited expression of the exogenous p53 is observed in skin and only endogenous mouse p53 was evident in liver of the same mouse. In contrast, a much lower level of exogenous p53 expression was observed in the tumor from the mouse injected i.v. with the unliganded lipoplex, LipA-p53.

is consistent with earlier reports that exogenous wtp53 induced endogenous p53 gene expression, possibly through the wtp53 transcriptional autoregulation $(26,52)$. However, only limited expression of the exogenous p53 is evident in skin and only endogenous mouse p53 was evident in liver of the same TfRscFv-LipA2-p53 immunolipoplex injected mouse. In contrast, a much lower level of exogenous p53 expression was observed in the tumor from the mouse i.v. injected with the unliganded LipA-p53 lipoplex (Fig. 8). The TfRscFv-immunolipoplex mediated systemic gene delivery was tumor-specific in that the liver showed no obvious exogenous p53 gene expression (Fig. 8), nor did other organs (data not shown). This experiment was repeated three times with representative results shown in Fig. 8. These results demonstrate that the exogenous p53 gene can be systemically delivered to, and efficiently expressed in, the tumor in vivo by the TfRscFvtargeting immunolipoplex.

\section{Increased Survival in a Nude Mouse Metastasis Model of Human Breast Cancer After Treatment with TfRscFv- LipA2-p53 in Combination with Docetaxel}

To examine the in vivo efficacy of the systemic p53 gene therapy with the TfRscFv-LipA2-p53 immunolipoplex, a nude mouse tumor metastasis model was employed. This tumor model uses a human breast cancer cell line, 435/LCC6, derived from mouse ascites of tumor cell line MDA-MB-435 (22). In this well-defined model, the mice begin to develop 
symptoms and die within a reproducible time period of about 30 days. Fig. 9(a) shows the animal survival curves of the nude mice after various treatments and Fig. 9(b) shows the result of a repeat experiment focusing on comparison of the two targeting ligands, TfRscFv and Tf. Docetaxel alone offered no benefit in terms of survival (median survival time 32 days), indicating that the tumor is highly chemoresistant. The systemic administration of TfRscFv-LipA2-p53 via the tail vein in combination with docetaxel significantly extended the lifespan of the animals beyond that of untreated control or the docetaxel alone group ( $p<0.0001$, Kaplan-
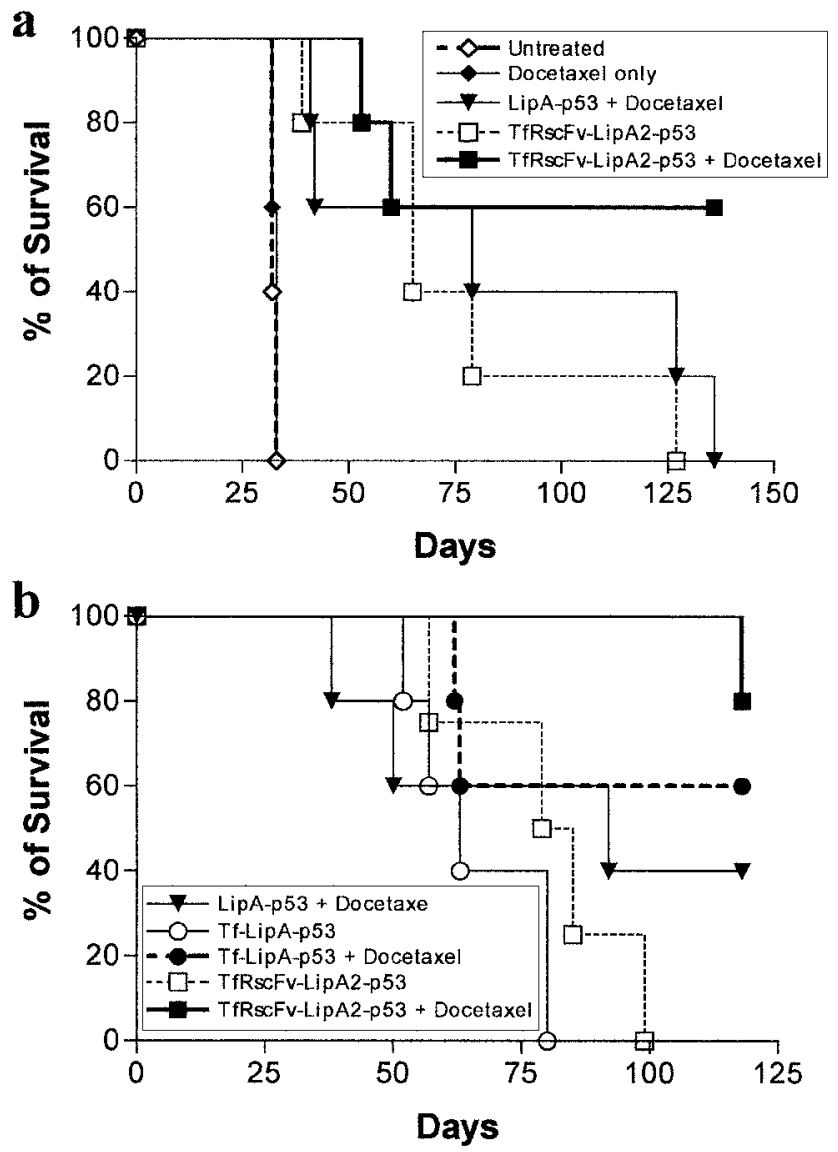

Fig. 9. Increased survival in a nude mouse metastasis model of human breast cancer after treatment with TfRscFv-LipA2-p53 in combination with docetaxel. Beginning 10 days after tumor cell injection, twice weekly doses of TfRscFv-LipA2-p53 (20 $\mu \mathrm{g}$ p53 DNA/0.3 ml) with or without docetaxel $(7.5 \mathrm{mg} / \mathrm{Kg})$ were intravenously administered (5 animals per group). A total of 10 injections were administered. (a) shows the animal survival curves of the nude mice after various treatments and (b) shows the result of a repeat experiment focusing on comparison of the two targeting ligands, TfRscFv and Tf. The systemic administration of TfRscFv-LipA2p53 via tail vein in combination with docetaxel significantly extended the life-span of the animals. Long term survivors were observed in the animals receiving the combination of TfRscFvLipA2-p53 and docetaxel, with $60 \%$ in the first study (A) and $80 \%$ in the second study (B), while no long term survivors were observed in animals receiving either treatment alone.
Meier Survival Analysis and Mantel-Haenszel Logrank Test). Moreover, TfRscFv-LipA2-p53 and docetaxel combination therapy showed significantly improved efficacy over the immunolipoplex without docetaxel $(p<0.005)$. Interestingly, the survival of animals treated with TfRscFv-targeting lipoplex plus docetaxel was not significantly different than that of the Tf-targeting lipoplex plus docetaxel $(p>0.1)$, but both treatments showed much better anti-tumor effect than that of the non-targeting lipoplex plus docetaxel $(p<0.05)$. More importantly, long term survivors were observed in the animals receiving the combination of TfRscFv-targeting p53lipoplex and docetaxel, with $60 \%$ in the first study (Fig. 9a) and $80 \%$ in the second study (Fig. 9b), while no long term survivors were observed in animals receiving either treatment alone. The systemic administration of the TfRscFv-immunolipoplex did not seem to be toxic to the animals. The results demonstrate that anti-TfR single-chain antibody can target the lipoplex specifically to tumors in vivo as efficiently as transferrin itself. This targeting leads to enhanced efficacy of systemic p53 gene therapy.

\section{Discussion}

Receptor-mediated endocytosis represents a highly efficient internalization pathway in eukaryotic cells $(9,27,28)$. The presence of a ligand on a lipoplex facilitates the entry of DNA into cells through binding of the ligand by its receptor on the cell surface followed by internalization of the bound complex. Once internalized, sufficient DNA escapes the endocytic pathway to be expressed in the cell nucleus. In addition to utilizing ligands to recognize corresponding receptors on tumor cells, specific antibodies can also be attached to the liposome surface to direct them to specific tumor surface antigens $(29,30)$. These immunoliposomes can deliver therapeutic drugs to a specific target cell population (31). Park et al. (32) reported that anti-HER-2 monoclonal antibody (MAb) Fab fragments conjugated to liposomes could bind specifically to a breast cancer cell line SK-BR-3 that overexpresses HER-2. The immunoliposomes were found to be internalized efficiently by receptor-mediated endocytosis via the coated pit pathway and also possibly by membrane fusion. Suzuki et al. (33) used anti-transferrin receptor monoclonal antibody conjugated immunoliposomes to deliver doxorubicin more effectively in human leukemia cells in vitro. Huwyler et al. (34) used anti-TfR monoclonal antibody immunoliposomes to deliver daunomycin to rat glioma (RT2) cells in vivo. These studies demonstrate the utility of immunoliposomes for tumor-targeted drug delivery. Therefore, the combination of cationic liposome-gene transfer and immunoliposome techniques would be a promising system for targeted gene delivery.

In the present study, we employed a biosynthetically lipid-tagged recombinant single chain Fv 
antibody fragment based on the anti-TfR monoclonal antibody 5E9, TfRscFv, to target cationic liposomes. The lipid-tagged TfRscFv can be incorporated into cationic liposomes with ease via either the lipid-film solubilization method or the direct anchoring method. The advantage of the direct anchoring method is that the TfRscFv is attached to the preformed liposomes, so that all TfRscFv are present on the surface of the liposomes and thereby available for binding to targets. This has been confirmed by their relatively higher binding activity and transfection efficiencies. The TfRscFv-targeting immunolipoplex showed enhanced tumor cell binding, improved gene delivery and transfection efficiencies both in vitro and in vivo. The p53 tumor suppressor gene was systemically delivered to the tumor xenografts in nude mice and functionally expressed. The duration of the functional p53 gene expression and the pharmacokinetics still need further studies. Our previous studies with Tflipoplexes indicate that $\mathrm{p} 53$ transgene expression in human tumor cells and xenografts are transient, peak at 48-72 hrs post transfection injection and diminish in 7-10 days $(4,16,28)$. The TfRscFvimmunolipoplex should have a similar pattern. This transient gene expression gives us the capability to control the transgene expression level and supports the twice a week i.v. administration strategy employed in the in vivo efficacy studies.

The TfRscFv has advantages over the Tf molecule itself for a number of reasons. First, the size of the TfRscFv $(\sim 30 \mathrm{kDa}$ with lipid tag) is much smaller than that of the Tf molecule $(\sim 80 \mathrm{kDa})$. Thus, the TfRscFv-liposome-DNA complex may exhibit better penetration into small capillaries characteristic of solid tumors. Second, as a recombinant protein, the smaller scFv also has practical advantages related to its production. Large scale production and strict quality control of the ScFv as well as ScFv-immunolipoplex will be required for this therapy to be used in human trials. Third, the scFv is a recombinant molecule, not a blood product like human $\mathrm{Tf}$, and therefore presents no regulatory issues related to potential contamination with blood borne pathogens. Additional advantages of using the ScFv relate to the fact that $\mathrm{Tf}$ interacts with the TfR with high affinity only after the ligand is loaded with iron. Large-scale production of liposomes containing iron-loaded Tf may present practical challenges. Use of SCFV enables the TfR on tumor cell to be targeted by a liposomal therapeutic complex that does not contain iron (itself implicated in cancer (35)). Fourth, without the Fc region, the problem of non-antigen-specific binding through Fc receptors is eliminated (36).

The size of a gene therapeutic is a critical parameter for its design, preparation, optimization and quality control. We employed photon correlation spectroscopy (PCS) to measure and monitor the sizes of the TfRscFv-immunoliposomes and immunolipoplexes.
The permeable size of the capillaries in a tumor is usually believed to be about $100 \mathrm{~nm}$ in diameter $(37,38)$. Therefore, the TfRscFv-Liposome-DNA immunolipoplexes prepared in this study are theoretically able to pass through the capillary wall to reach the target. Our in vivo results showing increased transgene expression in tumor and enhanced efficacy of systemic p53 gene therapy indicate that is very likely to be the case. This size limit is a prerequisite for systemic delivery systems, especially for genes. The PCS technique provides a convenient and robust way to measure the size and surface charge of a complex system. The preliminary analysis of TfRscFvimmunolipoplexes by electron microscopy (EM) with negative staining confirmed the results of PCS, and also provided insights into the structure and molecular arrangement of the complexes (Xu et al., Manuscript in preparation).

Abnormalities in the tumor suppressor gene, p53, have been identified in over $50 \%$ of breast cancers and have been linked to resistance to chemotherapy $(39,40)$. A role for p53 in the control of cellular proliferation by the regulation of cell cycle events and induction of programmed cell death (apoptosis) has been established (4). Since it appears that most anti-cancer agents work by inducing apoptosis $(41,42)$, inhibition of, or changes in this pathway may lead to failure of therapeutic regimens $(4,28)$. Loss or malfunction of this p53-mediated apoptotic pathway is one mechanism by which tumors become resistant to chemotherapy (43). Restoration of normal p53 function may therefore sensitize resistant breast cancers to treatment $(4,28)$. We have previously shown that the restoration of p53 function via p53 gene therapy resulted in sensitization of breast tumors to chemotherapeutic agents $(4,28,44)$. This sensitization is due to the restoration of p53-dependent apoptotic pathway in the tumor cells (4). The sensitization of tumors to chemotherapy could result in lowering the required effective dose of chemotherapeutic agents, correspondingly lessening the severe side effects, while improving the efficacy and decreasing the incidences of recurrence. Moreover, this combination approach can be applied to both primary and recurrent tumors, as well as metastases (4).

Docetaxel, a novel member of the taxoid family, has shown greater potency than paclitaxel in the treatment of advanced breast cancer and certain other solid tumors $(45,46)$. Thus, docetaxel is becoming an important part of the current first-line chemotherapy regime for human breast cancer (49-51). Its anti-tumor activity also relates to the induction of cellular apoptosis $(45,47,48)$. Therefore, restoration of functional p53 and the p53 mediated apoptotic pathway could result in increased efficacy of docetaxel. In fact, here we observed that the combination of docetaxel chemotherapy, and systemic administration of the wtp53 gene delivered by the TfRscFv-immunolipoplex did show improved efficacy 
with prolonged animal life-span in a human breast cancer metastasis model. Moreover, the systemic administration of the immunolipoplexes did not seem to be toxic to the animals. This study demonstrates the proof-of-principle of using TfRscFv-targeting immunolipoplexes with a defined size for systemic p53 gene therapy to improve the outcome of conventional chemotherapy. Thus, the TfRscFv-targeting of cationic immunolipoplex is a promising strategy to develop a targeted gene delivery system for systemic gene therapy of cancer.

\section{Acknowledgments}

We are grateful to Dr. David Fitzgerald for providing the plasmid pDFH2T-vecOK containing the TfRscFv cDNA, Dr. John de Kruif for providing the expression vector $\mathrm{pLPl}$, Dr. Arnold Levine for providing the plasmid pBP100, Ms. Tina Wilson and Kelle Reames for assistance with the in vivo animal studies, Dr. Wei-Qun Huang for assistance with Western analysis, Dr. Karen Creswell for assistance with flow cytometry analysis, and Leanne Sleer for assistance with the manuscript. This work was supported in part by NCI grant R01 CA45158 (E. C.) and NCI STTR Phase I grant R41 CA80449 (E. C.), and SynerGene Therapeutics, Inc.

\section{References}

1. Meng RD, EL-Deiry WS. (1999) Tumor suppressor genes as targets for cancer gene therapy. In: Lattime EC and Gerson SL, eds., Gene Therapy of Cancer, Academic Press, San Diego, CA. pp. 3-20.

2. Zhang W, Fujiwara T, Grimm EA, Roth JA. (1997) Advances in Cancer Gene Therapy. Adv. Pharmacol. 32: 289-333.

3. Chen QR, Mixson JA. (1998) Systemic gene therapy with p53 inhibits breast cancer: recent advances and therapeutic implications. Front. Biosci. 3: D997-D 1004.

4. Chang EH, XuL, Pirollo KF. (2000) Targeted p53 Gene Therapy Mediated Radiosensitization and Chemosensitization. In: Gutking JS ed. Signaling Networks and Cell Cycle Control: The Molecular Basis of Cancer and Other Diseases. The Humana Press Inc., Totowa, NJ. pp. 519-536.

5. Huang L, Viroonchatapan E. (1999) Introduction. In: Non-viral Vectors for Gene Therapy. Huang L, Hung MC and Wagner E. eds., Academic Press, San Diego, CA. pp. 3-22.

6. Ledley FD. (1995) Nonviral gene therapy: the promise of genes as pharmaceutical products. Hum. Gene Ther. 6: 1129-1144.

7. Felgner PL, Tsai YJ, Sukhu L, et al. (1995) Improved cationic lipid formulations for in vivo gene therapy. Ann. NY Acad. Sci. 772: 126-139.

8. Felgner PL. (1999) Progress in gene delivery research and development. In: Non-viral Vectors for Gene Therapy. Huang L, Hung MC and Wagner E. eds., Academic Press, San Diego, CA. pp. 26-38.

9. Christiano RJ, Curiel DT. (1996) Strategies to accomplish gene therapy via the receptor-mediated endocytosis pathways. Cancer Gene Ther. 3: 457-497.

10. Keer HN, Kozlowski JM, Tsai MC. (1990) Elevated transferrin receptor content in human prostate cancer cell lines assessed in vitro and and in vivo. J. Urol. 143: 381-385.

11. Rossi MC, Zetter BR. (1992) Selective stimulation of prostate carcinoma cell proliferation by transferrin. Proc. Natl. Acad. Sci. USA 89: 6197-6201.

12. Elliott RL, Elliott MC, Wang F, Head JF. (1993) Breast carcinoma and the role of iron metabolism. a cytochemical, tissue culture, and ultrastructural study. Ann. NY Acad. Sci. 698: 159-166.

13. Miyamoto T, Tanaka N, Eishi Y, Amagasa, T. (1994) Transferrin receptor in oral tumors. Int. J. Oral Maxillofac. Surg. 23: 430-433.

14. Thorstensen K, Romslo I. (1993) The Transferrin receptor: its diagnostic value and its potential as therapeutic target. Scand. J. Clin. Lab. Invest. Suppl. 215: 113-120.

15. Xu L, Pirollo KF, Chang EH. (1997) Transferrin-liposomemediated p53 sensitization of squamous cell carcinoma of the head and neck radiation in vitro. Hum. Gene Ther. 8: 467-475.

16. Xu L, Pirollo KF, Tang W, Rait A, Chang EH. (1999) Transferrinliposome-mediated systemic $p 53$ gene therapy in combination with radiation results in regression of human head and neck cancer xenografts. Hum. Gene Ther. 10: 2941-2952.

17. Keinanen K, Laukkanen ML. (1994) Biosynthetic lipidtagging of antibodies. FEBS Letters 346: 123-126.

18. de Kruif J, Storm G, van Bloois L, Logtenberg T. (1996) Biosynthetically lipid-modified human ScFv fragments from phage display libraries as targeting molecules for immunoliposomes. FEBS Letters 399: 232-236.

19. Haynes BF, Hemler M, Cotner T, et al. (1981) Characterization of a monoclonal antibody (5E9) that defines a human cell surface antigen of cell activation. J. Immunol. 127: 347-351.

20. Xu L, Pirollo KF, Rait A, Murray AL, Chang EH. (1999) Systemic p53 Gene Therapy In Combination with Radiation Results in Human Tumor Regression. Tumor Targeting 4: 92-104.

21. Chen L, Agrawal S, Zhou W, Zhang R, Chen J. (1998) Synergistic activation of p53 by inhibition of MDM2 expression and DNA damage. Proc. Natl. Acad. Sci. USA 95: 195-200.

22. Leonessa F, Green D, Licht T, et al. (1996) MDA435/LCC6 and MDA435/LCC6MDR1: ascites models of human breast cancer. Br. J. Cancer. 73: 154-161.

23. Laukkanen ML, Teeri TT, Keinanen K. (1993) Lipid-tagged antibodies: bacterial expression and characterization of a lipoprotein-single-chain antibody fusion protein. Protein. Eng. 6: $449-454$.

24. Laukkanen ML, Alfthan K, Keinanen K. (1994) Functional immunoliposomes harboring a biosynthetically lipid-tagged single-chain antibody. Biochemistry 33: 11664-11670.

25. New RRC. (1989) Preparation of liposomes. In: Liposomes-a practical approach. New RRC, Ed., IRL Press, Oxford, UK. pp. 33-104.

26. Pirollo KF, Hao Z, Rait A, Jang YJ, Fee WE Jr, Ryan P, Chiang Y, Chang EH. (1997) p53 mediated sensitization of squamous cell carcinoma of the head and neck to radiotherapy. Oncogene 14: 1735-1746.

27. Wagner E. (1999) Ligand-polycation conjugates for receptortargeted gene transfer. In: Non-viral Vectors for Gene Therapy. Huang L, Hung MC and Wagner E. eds., Academic Press, San Diego, CA. pp. 208-227.

28. Pirollo KF, Xu L, Chang EH. (2000) Non-viral gene delivery for p53. Curr. Opin. Mol. Ther. 2: 168-175.

29. Allen TM, Hansen CB, Zalipsky S. (1995) Antibody-targeted stealth liposomes. In: Stealth Liposomes, Lasic D., and Martin F. (Eds), CRC Press, Boca Raton, Florida. pp. 233-244.

30. Hansen CB, Kao GY, Moase EH, Zalipsky S, Allen TM. (1995) Attachment of antibodies to sterically stabilized liposomes: evaluation, comparison and optimization of coupling procedures. Biochim. Biophys. Acta. 1239: 133-144.

31. Mastrobattista E, Koning GA, Storm G. (1999) Immunoliposomes for the targeted delivery of antitumor drugs. Adv. Drug Deliv. Rev. 40: 103-127.

32. Park JW, Hong K, Carter P, et al. (1995) Development of antip185HER2 immunoliposomes for cancer therapy. Proc. Natl. Acad. Sci. USA 92: 1327-1331.

33. Suzuki S, Inoue $\mathrm{K}$, Hongoh A, Hashimoto Y, Yamazoe Y. (1997) Modulation of doxorubicin resistance in a doxorubicin-resistant human leukaemia cell by an immunoliposome targeting transferring receptor. Br. J. Cancer 76: 83-89.

34. Huwyler J, Yang J, Pardridge WM. (1997) Receptor mediated delivery of daunomycin using immunoliposomes: 
pharmacokinetics and tissue distribution in the rat. J. Pharmacol. Exp. Ther. 282: 1541-1546.

35. Weinberg ED. (1992) Roles of iron in neoplasia. Promotion, prevention, and therapy. Biol. Trace Elements Res. 34: 123140.

36. Pelegrin M, Marin M, Noel D, Piechaczyk M. (1998) Genetically engineered antibodies in gene transfer and gene therapy. Hum. Gene Ther. 9: 2165-2175.

37. Huang SK, Martin FJ, Friend DS, Papahadjopoulos D. (1995) Mechanism of stealth liposome accumulation in some pathological tissues. In: Stealth Liposomes, Lasic D., and Martin F. eds, CRC Press, Boca Raton, Florida. pp. 119-125.

38. Feng D, Nagy JA, Hipp J, Pyne K, Dvorak HF, Dvorak AM. (1997) Reinterpretation of endothelial cell gaps induced by vasoactive mediators in guinea-pig, mouse and rat: many are transcellular pores. J. Physiol. 504: 747-761.

39. Ozbun MA, Butel JS. (1995) Tumor suppressor p53 mutations and breast cancer: a critical analysis. Adv Cancer Res. 66: 71-141.

40. Allred DC, Elledge R, Clark GM, Fuqua SA. (1994) The p53 tumor-suppressor gene in human breast cancer. Cancer Treat. Res. 71: 63-77.

41. Kerr JF, Winterford CM \& Harmon BV. (1994) Apoptosis: Its significance in cancer and cancer therapy. Cancer 7: 2013-2026.

42. Yeung TK, Germond C, Chen X, Wang Z. (1999) The mode of action of taxol: apoptosis at low concentration and necrosis at high concentration. Biochem. Biophys. Res. Commun. 263: 398-404.

43. Lowe SW. (1995) Cancer therapy and p53. Curr. Opin. Oncol. 7: 547-553.

44. Xu L, Pirollo KF, Chang EH. (2001) Tumor-targeted p53-gene therapy enhances the efficacy of conventional chemo/radiotherapy. J. Control. Release 74: 115-128.
45. Hortobagyi GN. (1999) Recent progress in the clinical development of docetaxel (Taxotere). Semin. Oncol. 26: 32-36.

46. Zeng S, Chen YZ, Fu L, Johnson KR, Fan W. (2000) In vitro evaluation of schedule-dependent interactions between docetaxel and doxorubicin against human breast and ovarian cancer cells. Clin. Cancer Res. 6: 3766-3773.

47. Miyake H, Hara S, Arakawa S, Kamidono S, Hara I. (2001) Overexpression of Bcl-2 regulates sodium butyrate- and/or docetaxel-induced apoptosis in human bladder cancer cells both in vitro and in vivo. Int. J. Cancer 93: 26-32.

48. Muenchen HJ, Poncza PJ, Pienta KJ. (2001) Different docetaxel-induced apoptotic pathways are present in prostate cancer cell lines LNCaP and PC-3. Urology 57: 366-370.

49. Khayat D, Chollet $P$, Antoine EC, Monfardini S, Ambrosini G, Benhammouda A, Mazen MF, Sorio R, Borg-Olivier O, Riva A, Ramazeilles C, Azli N. (2001) Phase II study of sequential administration of docetaxel followed by doxorubicin and cyclophosphamide as first-line chemotherapy in metastatic breast cancer. J. Clin. Oncol. 19: 3367-3375.

50. Viens P, Roche H, Kerbrat P, Fumoleau P, Guastalla JP, Delozier T. (2001) Epirubicin-docetaxel combination in firstline chemotherapy for patients with metastatic breast cancer: final results of a dose-finding and efficacy study. Am. J. Clin. Oncol. 24: 328-335.

51. Hainsworth JD, Burris HA 3rd, Yardley DA, Bradof JE, Grimaldi M, Kalman LA, Sullivan T, Baker M, Erland JB, Greco FA. (2001) Weekly docetaxel in the treatment of elderly patients with advanced breast cancer: a Minnie Pearl Cancer Research Network phase II trial. J. Clin. Oncol. 19: 3500-3505.

52. Liu TJ, Zhang WW. Taylor DL, Roth JA, Goepfert H, Clayman GL. (1994) Growth suppression of human head and neck cancer cells by the introduction of a wild-type p 53 gene via a recombinant adenovirus. Cancer Res 54: 3662-3667. 